\title{
Interview with Future Medicinal Chemistry's US Senior Editor, Iwao Ojima
}

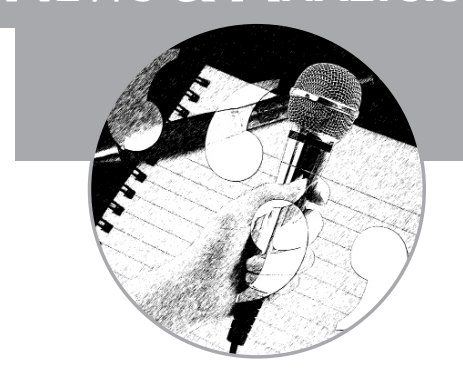

Professor Iwao Ojima studied at the University of Tokyo (Japan) before being appointed as a Senior Research Fellow and Group Leader at the Sagami Institute of Chemical Research. He is now Director of the Institute of Chemical Biology and Drug Discovery at State University of New York (USA) and has been a visiting professor in European, North American and Asian academic institutions. Professor Ojima agreed to serve as the US Senior Editor of Future Medicinal Chemistry when it launched in 2009 and continues to provide his expertise to the journal. Professor Ojima spoke to Future Medicinal Chemistry about why medicinal chemistry is such an exciting field to work in, the state of the pharmaceutical industry, and what features and issues make this journal unique.

Interview conducted by Isaac Bruce, Commissioning Editor.

Why do you enjoy being a medicinal chemist?

I enjoy the interdisciplinary and multidisciplinary interactions with many different experts in disparate fields. Medicinal chemistry is now in a unique and fantastic position to integrate various different fields. It used to be that a medicinal chemist would make lots of compounds for testing, optimize them and then give advanced drug candidates to process research experts. But, now, the medicinal chemist increasingly needs to interact with biologists and even physicians.

Observing these changes is fascinating and exciting: shifting from very traditional medicinal chemistry, such as chemical synthesis, to a more integrated science.

From the chemist's point of view, as regards small molecules, the chemists are the only scientists in a position to synthesize these compounds; the biologists cannot do it. In that sense, we chemists are in a very unique and advantageous position.

In silico testing, molecular dynamics and cell cultures are some of the many techniques that are now being used by medicinal chemists; do you think that the crossover of these fields and the use of these techniques make for a more well-rounded medicinal chemist? I really think so. Approximately 10 years ago in my own academic group we envisioned that the new-generation 'medicinal' chemists would have to learn biology seriously. If you are simply collaborating and sending out the compounds and just waiting for the evaluation by the biology groups, such a process is not productive. Ideally, we should do the preliminary biological testing ourselves. When you design and synthesize the compounds, you really want to see how they work! And if the compound does not work, then you can adapt as necessary. For us, this proved to be a very successful move. Initially, my students did have some reservations but it has worked out very well as it better allows researchers to see the fruits of their efforts immediately, which really stimulates their activities.

In parallel to this, I have been developing another type of new-generation medicinal chemist who have computational biology expertise besides chemical synthesis. We have a strong group of structural and computational biologists on campus, who are members of the Institute of Chemical Biology and Drug Discovery. When graduate students, who originally trained in synthetic organic chemistry, join us they learn computational biology by taking two-semester courses. This means they can integrate computational docking and in silico screening into their $\mathrm{PhD}$ research projects. This approach identifies a target protein, searching for hits by in silico screening commercially available compound libraries, select computational hit compounds, purchasing top-rated hit compounds from vendors and then actually testing the activity of those compounds by biological assays to identify hit or even lead compounds. Thus, the lead compounds selected move to the next iterative step, that is, rational design of optimization libraries, synthesis and biological as well as computational assays. This approach is completely different from that employed 20 years ago.

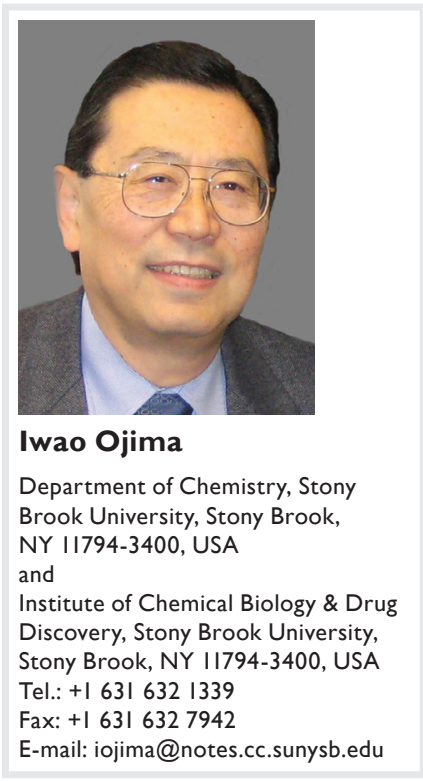

FUTURE
SCIENCE FSS 


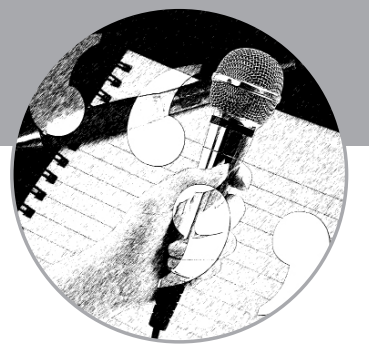

Which area of medicinal chemistry do you anticipate delivering the most promising advances over the coming 5-10 years?

Computational biology will definitely advance. Computational time and the speed of the computer have become extremely fast. In my laboratory and in our school, we can use a super computer to run various computational biology programs, and this is changing the way we do modern drug discovery. In that sense, in the next 5-10 years computational power will improve and how we use it will evolve too. The combination of the in silico screening and analysis, studying the interaction of the drug with proteins, will certainly advance but, beyond this, the drug metabolism and toxicity assessment via computational methods will make significant advances. In addition, chemical biology will keep providing a lot of useful tools to study various biological functions of the drug leads and candidates as well as interactions with, for example, target proteins, genes and transcription factors. Thus, chemical biology will play increasingly important roles in medicinal chemistry in the next decade.

There have been a series of well-documented cutbacks and closures in the pharmaceutical industry. How would you assess the current state of the industry?

In volume 3 issue 15, this journal published an 'Ask the Experts' feature [1] on this very issue. In addition, there is an excellent article by John Baldwin that also explores this issue [2]. It is true to say that it does not look good right now and there is a certain degree of pessimism.

The surprising number of big mergers has brought about a sharp decline in the number of 'big pharma'. 20 years ago we had approximately 30 big pharmaceutical companies and now we have only less than ten. That is a bad situation to be in, from the purely business point of view, the CEOs have decided to keep the big blockbuster drugs by absorbing the competitors! The danger is that big pharmaceutical companies will become too big - and when you become too big, movement becomes slower and decision-making takes longer. This trend is not good and, thus, I hope to see some sort of disintegration of big pharmaceutical companies.

Of course, outsourcing to China and India and the growth of the CRO have been very successful in cutting back the cost of R\&D. However, the east and the west will need to find a way to collaborate and find a way of sustaining the wealth generated. It may be too optimistic to say this, but I do think that more jobs will be created in the west in the coming years, which may revitalize the industry. One problem, of course, is that CEOs often appear to focus on the very short-term benefit and returning something to the shareholders. This has affected the long-term strategy of the industry.

Q How has the situation in industry affected those in academia?

This rather depressing situation in pharmaceutical industries has undoubtedly affected the job situation for new PhD and MS medicinal chemists, which has caused substantial decline in the number of graduate students who are interested in synthetic organic and medicinal chemistry in the USA. This is a serious concern. On the other hand, the grim situation in pharmaceutical industry has stimulated the drug discovery activity in academia, especially in the less profitable areas, and promoted active industry-academia collaboration. For example, big pharmaceutical companies were previously very active in the area of antibiotics and antimicrobials, which are still providing substantial earnings, yet they are not investing research funds for the development of new antibacterial therapeutics. There should be a responsibility of the pharmaceutical industry to deal with these serious infectious diseases in the world. When the pharmaceutical companies cannot afford to spend money to do basic research, then it is wise for them to collaborate with academia. The prospect of these industry-academia collaborations is very bright and if it is organized properly, it would be highly productive and stimulating for academic researchers who have strong interest in drug discovery. Of course, historically, there have been many spin-off companies from academia that later have become big biotechnology or pharmaceutical companies. Those facts clearly indicate a very high potential of academic research in drug discovery.

Q Thinking about your role as senior editor of the journal, how do you think the journal has progressed since it launched in 2009?

Future Medicinal Chemistry has progressed extremely well. It has taken a highly innovative approach, meaning it is completely different to other academic journals by combining the characters of journals and magazines. Future Medicinal Chemistry offers a good balance of high-quality reviews and 
research articles, news and analysis, commentaries and editorials on a range of issues of interest to not only those in academia and industry, but also related professions such as regulatory affairs and intellectual property.

The first impact factor given in June 2011 was 1.424 and now in June 2012 it is 2.522 . This rise demonstrates the caliber of content being published in what is still a young journal.

Q Are there any articles published recently you wish to highlight that you believe have provided considerable insight to their area?

Of particular note for me, given my own research interests, is the two-part special focus issue on targeted oncology [3-20] guest edited by David Thurston (King's College, London, UK). These issues were eye catching given the general consensus that targeted chemotherapy may be moving into its 'golden age'. Also, the field is seeing notable successes in terms of a personalized medicine approach, unlike the situations in other medical areas.

Which other special issues would you recommend?

The two-part issue guest edited by Takushi Kaneko (TB Alliance) on neglected diseases [21-38]. This is an area that is often overlooked by other journals. Malaria kills several million people and there are many other major tropical diseases that do not yet have an effective treatment. This special focus makes us aware of the problems and reminds us of the opportunities to contribute to $\mathrm{R} \& \mathrm{D}$ in this area. We also have a special issue on malaria coming up in December 2012, guest edited by Jeremy Burrows (Medicines for Malaria Venture) to maintain the journal's commitment to covering research in this area.

Q In what ways do you believe that Future Medicinal Chemistry will continue to meet the needs of the community?

The acquisition editors and I are in regular communication with the aim of ensuring that we cover the most active, but also emerging, areas of research endeavor. We are very mindful of remaining abreast of developments in medicinal chemistry and allied disciplines, while also maintaining the journal's unique style. To achieve this, we place a strong emphasis on working with our excellent international editorial board. I look forward to continuing working with everyone at the journal and seeing Future Medicinal Chemistry go from strength to strength.

\section{Financial \& competing interests disclosure}

The author has no relevant affiliations or financial involvement with any organization or entity with a financial interest in or financial conflict with the subject matter or materials discussed in the manuscript. This includes employment, consultancies, honoraria, stock ownership or options, expert testimony, grants or patents received or pending, or royalties.

No writing assistance was utilized in the production of this manuscript.

\section{References}

1 Cottens S, Eaton M, Fuhr J et al. Ask the experts: future of the pharmaceutical industry. Future Med. Chem. 3(15), 1863-1872 (2011).

2 Baldwin JJ. Is drug discovery dead? Future Med. Chem. 3(15), 1873-1876 (2011).

3 Hevey R, Ling C-C. Global financial challenge: opportunities for strengthening $\mathrm{R} \& \mathrm{D}$ research in targeted drug delivery. Future Med. Chem. 4(1), 1-5 (2012).

4 Sullivan CG. US Supreme Court could reshape Hatch-Waxman's same labeling requirement. Future Med. Chem. 4(1), 7-8 (2012).

5 GJA Gallant. Are the large pharmaceutical and biotechnology companies driving the discovery, research and development of targeted cancer therapies? Future Med. Chem. 4(1), 13-17 (2012).
6 Lee T, Pelletier J. Eukaryotic initiation factor 4F: a vulnerability of tumor cells. Future Med. Chem. 4(1), 19-31 (2012).

7 Ojima I, Zuniga ES, Berger WT, Seitz JD. Tumor-targeting drug delivery of new-generation taxoids. Future Med. Chem. 4(1), 33-50 (2012).

8 Węsierska-Gądek J, Składanowski A. Therapeutic intervention by the simultaneous inhibition of DNA repair and type I or type II DNA topoisomerases: one strategy, many outcomes. Future Med. Chem. 4(1), 51-72 (2012).

9 Burden RE, Caswell J, Fay F, Scott CJ. Recent advances in the application of antibodies as therapeutics. Future Med. Chem. 4(1), 73-86 (2012).

10 Carragher NO, Unciti-Broceta A, Cameron DA. Advancing cancer drug discovery towards more agile development of targeted combination therapies. Future Med. Chem. 4(1), 87-105 (2012). 
Gallick GE, Corn PG, Zurita AJ, Lin S-H. Small-molecule protein tyrosine kinase inhibitors for the treatment of metastatic prostate cancer. Future Med. Chem. 4(1), 107-119 (2012).

12 Lee MS. Systematic prioritization of cancer combination therapies: are we really on target? Future Med. Chem. 4(4), 387-389 (2012).

13 Węsierska-Gądek J, Kramer MP. The impact of CDK inhibition in human malignancies associated with pronounced defects in apoptosis: advantages of multi-targeting small molecules. Future Med. Chem. 4(4), 395-424 (2012).

14 Cherblanc F, Chapman-Rothe N, Brown R, Fuchter MJ. Current limitations and future opportunities for epigenetic therapies. Future Med. Chem. 4(4), 425-446 (2012).

15 Wilken JA, Badri T, Cross S et al. EGFR/HERtargeted therapeutics in ovarian cancer. Future Med. Chem. 4(4), 447-469 (2012).

16 Rangwala S, Zhang C, Duvic M. HDAC inhibitors for the treatment of cutaneous T-cell lymphomas Future Med. Chem. 4(4), 471-486 (2012).

17 Grzybowska-Izydorczyk O, Smolewski P. mTOR kinase inhibitors as a treatment strategy in hematological malignancies. Future Med. Chem. 4(4), 487-504 (2012)

18 Gryder BE, Sodji QH, Oyelere AK. Targeted cancer therapy: giving histone deacetylase inhibitors all they need to succeed. Future Med. Chem. 4(4), 505-524 (2012).

19 Dalla Via L, Nardon C, Fregona D. Targeting the ubiquitin-proteasome pathway with inorganic compounds to fight cancer: a challenge for the future. Future Med. Chem. 4(4), 525-543 (2012).

20 Hevey R, Ling C-C. Recent advances in developing synthetic carbohydrate-based vaccines for cancer immunotherapies. Future Med. Chem. 4(4), 545-584 (2012).

21 Kaneko T. Drugs for neglected diseases: part I. Future Med. Chem. 3(10), 1235-1237 (2011).

22 McKerrow J. Interview with James McKerrow. Future Med. Chem. 3(10), 1243-1246 (2011).

23 Ginsberg A. Research Spotlight: The TB Alliance: overcoming challenges to chart the future course of TB drug development. Future Med. Chem. 3(10), 1247-1252 (2011).

24 Ruminski PG. From bench to clinic: bridging the translational gap in neglected disease drug development. Future Med. Chem. 3(10), 1253-1257 (2011).

25 Jacobs RT, Plattner JJ, Nare B et al. Benzoxaboroles: a new class of potential drugs for human African trypanosomiasis. Future Med. Chem. 3(10), 1259-1278 (2011).

26 Robertson SA, Renslo AR. Drug discovery for neglected tropical diseases at the Sandler Center. Future Med. Chem. 3(10), 1279-1288 (2011).

27 Seebeck T, Sterk GJ, Ke H. Phosphodiesterase inhibitors as a new generation of antiprotozoan drugs: exploiting the benefit of enzymes that are highly conserved between host and parasite. Future Med. Chem. 3(10), 1289-1306 (2011).

Pollastri MP, Campbell RK. Target repurposing for neglected diseases. Future Med. Chem. 3(10), 1307-1315 (2011).

29 de Hostos EL, Choy RKM, Nguyen T. Developing novel antisecretory drugs to treat infectious diarrhea. Future Med. Chem. 3(10), 1317-1325 (2011).

30 Kaneko T. Drugs for neglected diseases: part II. Future Med. Chem. 3(11), 1329-1330 (2011).

31 Edlin C. The importance of patent sharing in neglected disease drug discovery. Future Med. Chem. 3(11), 1331-1334 (2011).

32 Nwaka S. Interview with Solomon Nwaka. Future Med. Chem. 3(11), 1339-1344 (2011).

33 Guillemont J, Meyer C, Poncelet A, Bourdrez X, Andries K. Diarylquinolines, synthesis pathways and quantitative structure-activity relationship studies leading to the discovery of TMC207. Future Med. Chem. 3(11), 1345-1360 (2011).

34 Ioset J-R, Chang S. Drugs for neglected diseases initiative model of drug development for neglected diseases: current status and future challenges. Future Med. Chem. 3(11), 1361-1371 (2011).

35 Kaneko T, Cooper C, Mdluli K. Challenges and opportunities in developing novel drugs for TB. Future Med. Chem. 3(11), 1373-1400 (2011).

36 Burrows JN, Leroy D, Lotharius J, Waterson D. Challenges in antimalarial drug discovery. Future Med. Chem. 3(11), 1401-1412 (2011).

37 Nzila A, Ma Z, Chibale K. Drug repositioning in the treatment of malaria and TB. Future Med. Chem. 3(11), 1413-1426 (2011).

38 Mukherjee T, Boshoff $\mathrm{H}$. Nitroimidazoles for the treatment of TB: past, present and future. Future Med. Chem. 3(11), 1427-1454 (2011). 